\title{
The Effect of Canned Products on Human Body
}

\author{
Olatinpo Morayo Kemi ${ }^{1, *}$, Ogundowole Thompson Olubodun ${ }^{2}$, Famojuro Olusegun Olabisi ${ }^{3}$ Makinwa Olutobi \\ Joshua $^{4}$, Babatunde-Ikare Oluyemisi Victoria ${ }^{5}$ And Adebayo Mary Taiwo ${ }^{8}$ \\ Rufus Giwa Polytechnic Owo \\ Owo, Nigeria
}

*Corresponding author's email: olatinpomorayo [AT] gmail.com and jimohol [AT] yahoo.co.uk

\begin{abstract}
The use of canned products has become one of the defining characteristics of modern life. Canning is a method of preserving food by first sealing it in air-tight jars, cans or pouches, and then heating it to a temperature that destroys contaminating microorganisms that can either be of health or spoilage concern because of the danger posed by several spore-forming thermo-resistant microorganisms, such as Clostridium botulinum (the causative agent of botulism). Bisphenol A (BPA) is constantly discharged at trace levels in food packed in metal cans with PVC lining. $B P A$ is a known endocrine or hormone disruptor and is implicated in diseases ranging from infertility, obesity, breast and prostate cancer, to diabetics, thyroid malfunction and attention deficit syndrome. This represents a cause for concern because of potential effects of Bisphenol A to human health. This research presents the report on the effect of BPA on human and possible way to reduce it.
\end{abstract}

Keywords-Canned Products, Bisphenol A (BPA), Food, Clostridium, Microorganism

\section{INTRODUCTION}

Canning has become one of the defining characteristics of modern life. Few of us can imagine living without canning products. Canning is a method of preserving food by first sealing it in air-tight jars, cans or pouches, and then heating it to a temperature that destroys contaminating microorganisms that can either be of health or spoilage concern because of the danger posed by several spore-forming thermo-resistant microorganisms, such as Clostridium botulinum (the causative agent of botulism). There are four metals that are commonly used for the packaging of food. These are steel, aluminium, tin and chromium. Today the opportunity for tin in canning become a great industry, material like tinplate and aluminium have become universally adopted for the manufacture of containers and closures for food and beverage, largely due to several important qualities of containers of these metals. These include their mechanicals strength and resistance to working, low of temperature and ideal surface for decoration and lacquering. Containers are also able to have their temperature, humidity, and gas atmosphere controlled, this is necessary in particular situations such as the transportation of frozen foods, chilled meats and fresh fruits and vegetables. Food jars and cans must protect their contents, often under severe conditions. They must maintain an airtight seal even under pressure, and prevent changes to food taste, odour, appearance and texture. The best possible containers are interchangeable to meet the needs of multiple food manufacturers. They must be resistant to damage during handling, cost competitive and have minimal environmental and human health impacts. Bisphenol A (BPA)-based materials are pervasive in the U.S. economy (USEPA 2010). BPA is a high production volume (HPV) chemical widely used in manufacturing polycarbonate (PC) plastics and epoxy resins, including those commonly found in infant formula cans, baby bottles and baby food jar lids. Research has shown that BPA is a hormone-disrupting chemical found in the urine of nearly all individuals tested by the Centers for Disease Control and Prevention (CDC) and the National Health and Nutrition Examination Survey, indicating widespread exposure to BPA in the United States population (Calafat et al, 2008). Exposure to BPA occurs when BPA leaches into food or beverage products and is subsequently ingested by the individual. BPA leaches into food and beverage products when the BPA-containing-packaging is heated, either during the manufacturing process (e.g., formula preparation, canning process) or in the home directly by individuals. Exposure to BPA may also occur from dental treatments (e.g., dental sealants, composite fillings), handling of cash register receipts (i.e., thermal printer paper) and numerous other sources. However, the focus of this assessment is exposure to BPA from infant formula cans and baby food jar lids. The report reveals that BPA is a routine contaminant in canned foods.

\section{Canning Types}

Pressure canning foods with low acidity need sterilization by canning under conditions of both high temperature (116$\left.130^{\circ} \mathrm{C}\right)$ and pressure. 


\section{PRESSURE CANNER}

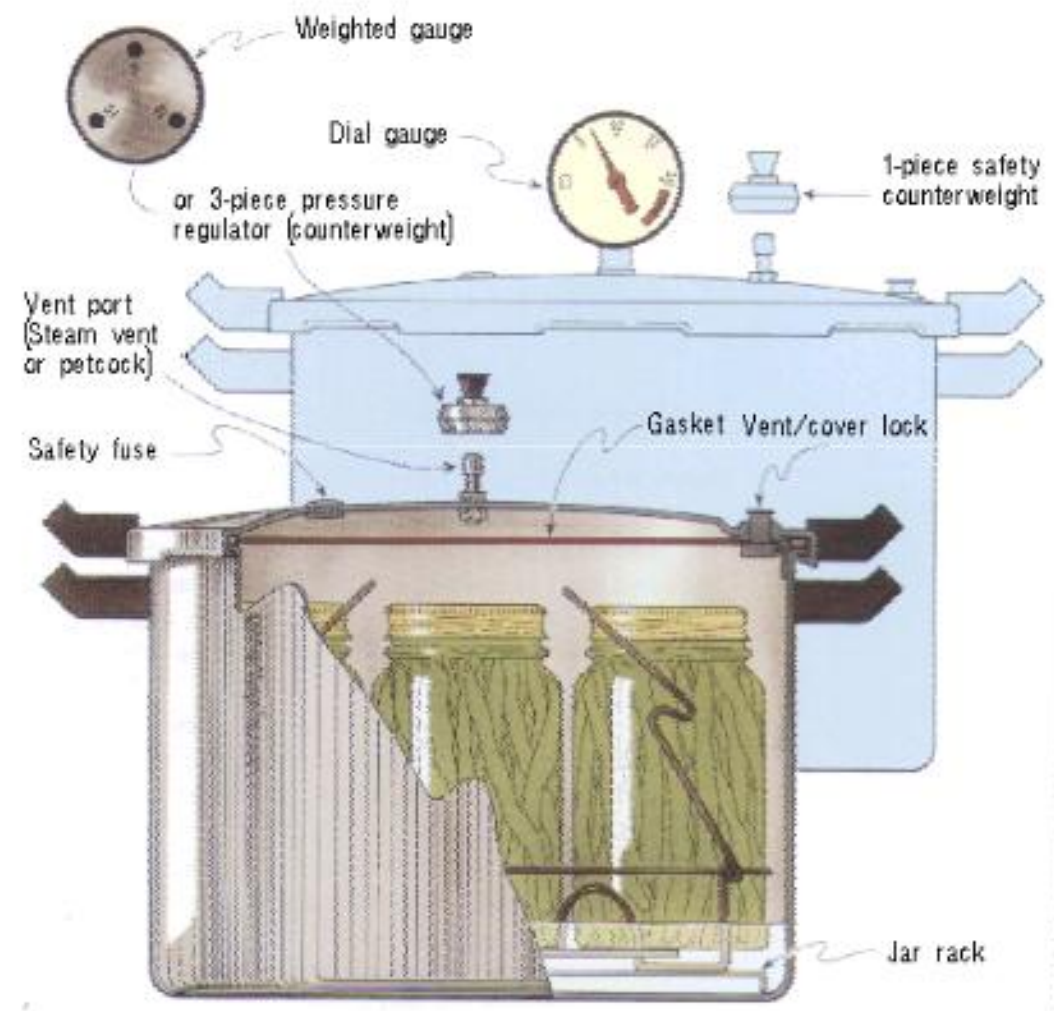

Sources: as cited by ISEKI- Food2 "1 Module 1 canning introduction"

Water Bath Canning: the only foods that may be safely canned in boiling water (without high pressure) are highly acidic foods with a $\mathrm{pH}$ below 4.6

\section{BOILING WATER BATH CANNER}

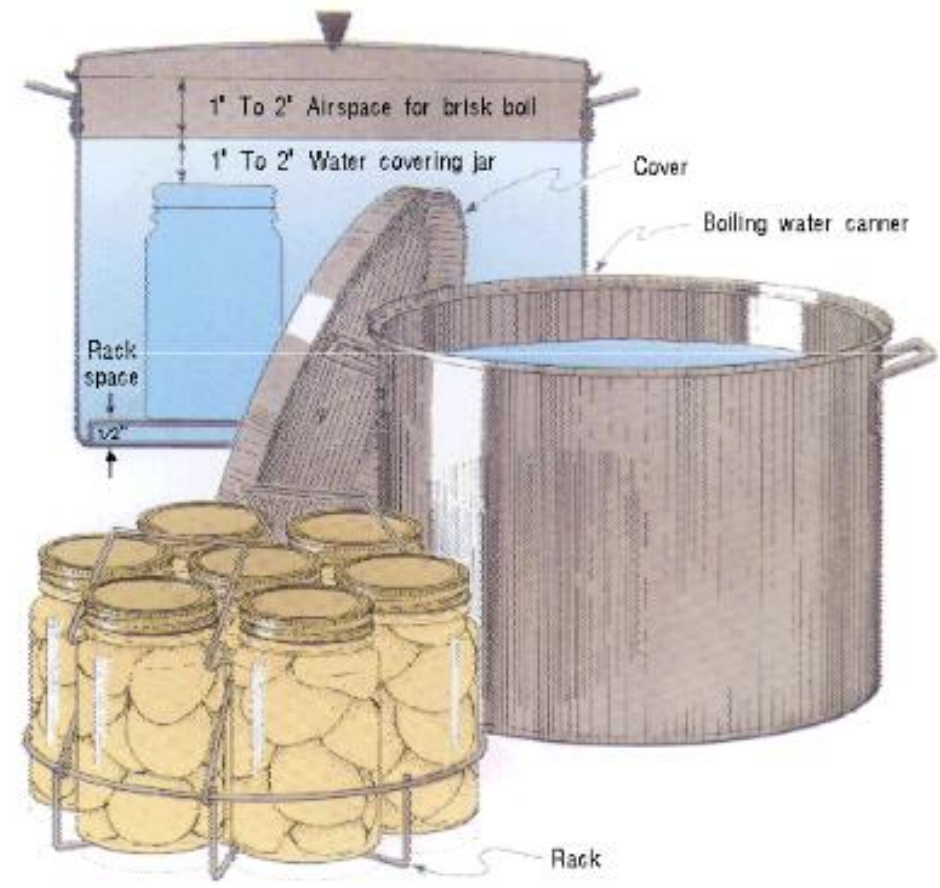

Sources: as cited by ISEKI- Food2 "1 Module 1 canning introduction" 


\section{Effects of canning on foods}

\section{COLOUR}

- The time-temperature combinations used in canning have effect on natural occurring pigments in foods.

- In fruits and vegetables, chlorophyll is converted to phenophtin, carotenoids are isomerised from 5, 6- epoxides to less intensely coloured 5, 8-epoxides, and anthocyanins are degraded to brown pigments.

- Discolouration of canned foods during storage occurs, i.e. when iron or tin react with anthocyanins to form a purple pigment, or when colourless leucoanthocyanins form pink anthocyanin complex in some varieties of pears and quinces.

\section{FLAVOUR AND AROMA}

- In canned meats there are complex changes, for example pyrolysis, deamination and decarboxylation of amino acids, degradation.

- In fruits and vegetables, changes are due to complex reactions which involve the degradation, recombination and volatilisation of aldehydes

\section{METHOD AND MATERIALS}

\section{BPA leaches into our food}

Unfortunately, BPA leaches from plastic containers into food and liquids and seeps out of food can linings. The scientific literature confirms that BPA is leached from countless consumer products and food contact materials and is released during its production into the environment (see Table 1). The amount of BPA that leaches is related to the type of food or liquid, the temperature and the heating time. Alarmingly, this leaching occurs under normal conditions of use. Leached BPA has been detected in vegetables, fish, fruit (including fresh), canned instant coffee, powdered milk and infant formula, canned milk and honey. BPA has also been found to migrate from polyvinyl chloride or PVC hoses and water storage tanks, contributing to the possible contamination of drinking water. An unexpected source of BPA may be fresh fruit and vegetables grown in greenhouses, as the chemical appears to migrate from the PVC panels used for the walls of greenhouses into the indoor atmosphere.

Table 1: major sources and modes of Bisphenol A (BPA) exposure

\begin{tabular}{|c|c|}
\hline Baby bottles & $\begin{array}{l}\text { Leaching from bottle into milk increases with the temperature of } \\
\text { the content, length of contact with the bottle and significantly after } \\
\text { repeated use. }\end{array}$ \\
\hline Polycarbonate plastic bottles & 55 fold increase in leaching when filled with boiling water. \\
\hline Microwave plastic containers & Leaching increases with heating of containers \\
\hline Polyvinyl chloride plastic wraps & $\begin{array}{l}\text { Leaching observed when in contact with water, olive oil or acetic } \\
\text { acid. }\end{array}$ \\
\hline Paper towels from recycled paper & $\begin{array}{l}\text { Bisphenol } \mathrm{A} \text { is used in the production of thermal paper. Different } \\
\text { types of recycled paper contain very different levels of BPA. }\end{array}$ \\
\hline Polycarbonate plastic tubing & Leaching levels greatest in river water \\
\hline Canned food lining & $\begin{array}{l}\text { Leaching into foods, including vegetables, fish, fruit, instant } \\
\text { coffee, powdered milk and infant formula. }\end{array}$ \\
\hline Fresh food & $\begin{array}{l}\text { Leaching from PVC in glass house panels via air onto fruit and } \\
\text { vegetables. }\end{array}$ \\
\hline
\end{tabular}

Sources: as cited by Vandenberg et al. 2007, Lopez-Espinoza et al. 2007, Le et al. 2008.

The potential overall environmental contamination due to BPA production is considerable and largely unacknowledged. BPA has been found in freshwater, seawater, landfill leachates (the liquid that drains from landfill), air, and dust particles. Human exposure to BPA is worldwide and pervasive. Numerous studies have found BPA in human serum, urine, amniotic fluid, follicular fluid, placental tissue, and umbilical cord blood despite the chemical being metabolised (ie. broken down) in the human body within 6 hours. The conclusion is that we are continuously and permanently exposed to quantities of BPA through the food we consume and the liquids we drink.

\section{Uses of Bisphenol A In Food Contact Materials}

BPA is present in certain food contact materials because it is used in the production of polycarbonate and epoxy-phenolic resins. Polycarbonate (PC) is a plastic widely used in articles such as infant feeding bottles, tableware (plates, mugs, jugs, and beakers), microwave ovenware, storage containers, returnable water and milk bottles, and refillable water containers. $\mathrm{PC}$ is also used for water pipes. 
Epoxy-phenolic resins are used as an internal protective lining for food and beverage cans and as a coating on metal lids for glass jar and bottles. Epoxy-phenolic resins are also used as a surface-coating on residential drinking water storage tanks and vine vats.

\section{Human Health Hazard}

Listed below is a synopsis of recent health effects documented in primary literature sources and excerpted from $A n$ Update on the Recently Published Peer-Reviewed Scientific Literature on Bisphenol A (BPA) (Vandenberg, 2012a):

- A 2009 study reported that prenatal exposure to females was associated with an increase in hyperactivity and aggression in 2-year-old girls (Braun et al., 2009). In a follow-up assessment of this cohort of children, average maternal BPA levels were associated with an increase in anxiety and hyperactivity, and poorer emotional control and inhibition in 3-year-old girls (Braun et al., 2011b). These results suggest that the behavior of BPAexposed girls was masculinized. This developmental behavior result has been recorded in animal studies, which have indicated that BPA can masculinize behaviors of female rodents, and may feminize the behaviors of male rodents (Adewale et al., 2011; Patisaul et al., 2006; Patisaul et al., 2009; Rubin et al., 2006).

- Maternal BPA exposures may be associated with an increase in premature births (Cantonwine et al., 2010; Chou et al., 2011; Miao et al., 2011b). Maternal exposure to BPA during pregnancy was also associated with decreased anogenital distance in males (Miao et al., 2011a), suggesting feminization of male offspring. Maternal BPA levels also influenced newborn hormone levels that are associated with lipid metabolism (Chou et al., 2011). These results are consistent with a study in mice documenting disruption of glucose homeostasis in mothers and their male offspring as a function of increased BPA exposure (Alonso-Magdalena et al., 2010b). Offspring may therefore be at risk for diabetes or obesity later in life.

- BPA activates the human pregnane X receptor (Sui et al., 2012), which is involved in lipid homeostasis, in addition to steroid and xenobiotic chemical metabolism. BPA may affect other endocrine parameters in addition to reproductive hormones and possibly metabolic homeostasis. Specifically, higher BPA levels were associated with decreased thyroid hormone levels in adults (Meeker et al., 2010a; Meeker and Ferguson, 2011).

\section{The Danger of Bisphenol A (BPA) is Implicated In Many Diseases such as cancer}

Knowledge of potentially hazardous metals in the ecosystem forms the central theme of canned food contamination by heavy metals. Heavy metal is a term, given to the group of metals and metalloids with atomic density greater than $5 \mathrm{~g} / \mathrm{cm}^{3}$, usually associated with pollution and toxicological problems (Abdulrahman and Itodo, 2006).

There are a large number of studies published in the scientific literature describing the results of laboratory animal studies. These include studies of traditional designs (following internationally agreed guidelines and in compliance with Good Laboratory Practice) carried out to assess the toxicity of BPA, as well as a wide variety of research studies examining possible effects following exposure to low doses of BPA during critical periods of development. This might result in adverse health outcomes later in life due to its oestrogenic or other biological properties (Sekizawa, 2008).

Some baby bottles, water bottles, and other clear plastic containers are made of polycarbonate plastic, a polymer made with the chemical bisphenol A (BPA). BPA is a hormone-disrupting chemical that in animal studies has been associated with reproductive abnormalities such as lower sperm counts, hormonal changes, enlarged prostate glands, abnormalities in the number of chromosomes in eggs, and pre-cancerous changes in the breast and prostate. It also has been associated with obesity and insulin resistance condition that commonly precedes the development of diabetes (Vom Saal et al. 2008). Tests have shown that more than 93 per cent of the general population has some BPA in their bodies (Calafat A.M et al. 2004). In animal studies, exposure on par with the amount of BPA most of us now have in our bodies has been shown to cause health abnormalities. Scientific research has shown that BPA is a known and proven endocrine disrupting chemical (a chemical that disturbs the hormone system). A 2007 scientific review linked exposure to BPA with an increased risk of cancer of the hematopoietic system (eg. marrow, spleen, tonsils, and lymph nodes), a significant increase in cell tumours of the testes and an alteration of the number of chromosomes in some cells and tissues (potentially leading to mutations and ultimately cancer). Additionally, early life exposure may induce or predispose humans to an increased risk of breast cancer. When exposure occurs during foetal or early childhood development, BPA may increase a person's susceptibility to cancer in later life by affecting their genetic developmental 'programming'

Alarmingly, a 2007 study showed that BPA can alter how genes are expressed (i.e. turned on or off) and that "low dose BPA exposure during pregnancy has multi-generational consequences: it increases the likelihood of chromosomally abnormal grandchildren". In humans, abnormal chromosomes may lead to miscarriages, death soon after birth or conditions such as Down's syndrome and Turner syndrome.

Barely a month goes by without new scientific studies being released linking BPA to a variety of human health problems. A study published in September 2008 linked Bisphenol A to heart disease, diabetes, and liver abnormalities in adults. A further study released in October 2008 found that BPA interferes with chemotherapy used to treat breast cancer, raising the possibility that the chemical undermines the efficacy of cancer-fighting drugs.

In humans, following oral exposure, BPA is transformed to the BPA monoglucuronide metabolite in a very efficient first pass effect in the gut and liver, whereas rodents suffer from prolonged exposure to free BPA due to enterohepatic 
circulation. It has been argued that BPA may be de-conjugated in several tissues and may not be rapidly cleared from the body of human embryos, which are exposed through the placenta, and of new born, which may therefore be a particularly sensitive subpopulation. As regards the latter, however, the European Food Safety Authority (EFSA) has issued in 2008 an opinion stating that new born can also rapidly eliminate BPA (EFSA, 2008).

\section{Chemical characteristics and function of BPA}

BPA (Chemical Abstracts Service [CAS] number 80-05-7) is manufactured by condensation of 2 mol phenol with 1 mol acetone in the presence of an acid catalyst such as hydrogen chloride (O'Neil 2006, Ullmann 2003). The molecular formula for BPA is $\mathrm{C}_{15} \mathrm{H}_{16} \mathrm{O} 2$ and the 2dimensional and 3-dimensional structures are shown in Figures 1 and 2.
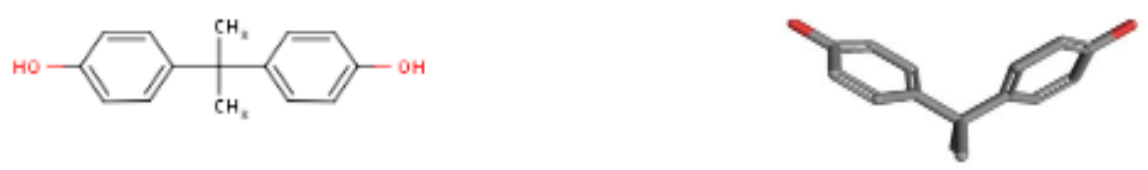

Figure 1. 2D Structure (NLM TOXNET 2012) Figure 2. 3D Conformer (PubChem 2012)

Table 2: Chemical/Physical Properties of BPA

\begin{tabular}{|l|l|l|}
\hline Parameter & Value/Description & Source \\
\hline Molecular Weight & $228.29 \mathrm{~g} / \mathrm{mol}$ & O'Neil 2006 \\
\hline Boiling Point & $220 \mathrm{deg} \mathrm{C}$ at 4 mm Hg & O'Neil 2006 \\
\hline Melting Point & $\begin{array}{l}150-155 \mathrm{deg} \mathrm{C} \text { (solidification } \\
\text { range) }\end{array}$ & O'Neil 2006 \\
\hline Density/Specific Gravity & 1.195 at 25 deg C/25 deg C & Lewis 2001 \\
\hline $\begin{array}{l}\text { Octanol/Water Partition } \\
\text { Coefficient }\end{array}$ & $\log$ Kow $=3.32$ & Hansch et al. 1995 \\
\hline Water Solubility & $120 \mathrm{mg} / \mathrm{L}$ at 25 deg C & Dorn PB et al. 1987 \\
\hline Vapor Pressure & $3.91 \times 10^{-7} \mathrm{~mm} \mathrm{Hg} \mathrm{at} \mathrm{25} \mathrm{deg} \mathrm{C}$ & USEPA 2004 \\
\hline Henry's Law Constant & $1.0 \times 10^{-11}$ atm-cu m/mol at 25 deg & USEPA 2004 \\
\hline Color/Form & C & O'Neil 2006 \\
\hline Odor & White crystals or flakes & O'Neil 2006 \\
\hline
\end{tabular}

\section{Rationale for Selection of BPA in lieu of Alternatives}

Selection of BPA products in lieu of suitable alternatives is manufacturer-specific. As noted previously, BPA-based materials are largely chosen for their high performance characteristics though another driving force is that BPA is inexpensive to manufacture making it suitable for mass production (Pierce and Caliendo, July 2012).

\section{Evaluation of the Possible Alternatives to Bisphenol A}

Bisphenol A is considered to be readily biodegradable and not bio-accumulative but toxic to aquatic organisms. It does thus not fulfil the criteria for classification as regards the environment but further discussion is needed as the observed effects at low concentrations of bisphenol A in long term toxicity studies justify the application of suitable risk and safety phrases (EU, 2003A).

From an environmental point of view the alternative polyester and polyamide, depending on the specific substances, may turn out to cause less harmful effects than BPA whereas polymerised rosin and monomers from polyacrylates may cause the same or more hazardous effects on the environment as bisphenol A. From the health point of view the possible alternatives, polyesters and polyamides depending on the specific substances, may turn out to cause less harmful effects than BPA, whereas some polyacrylates may be irritating to eyes, respiratory system and skin and polymerised rosins may cause sensitisation by skin contact. Bisphenol A is known to be irritating to respiratory system, cause risk of serious damage to eyes and sensitisation by skin contact. 
Furthermore, bisphenol A is on the list of substances, which are suspected as endocrine disrupters, and it has been suggested to classify it with R62 (possible risk of impaired fertility) (EU, 2003A). None of the mentioned alternatives are on this list but it should be mentioned that potential endocrine disrupting effects have most likely not been examined for the alternatives. The environmental and health effect of the alternative will, however, totally depend on the specific chemical compound in focus including possible migration of monomers etc. and the assessment should be revised on the basis of the properties of the specific chemical compound.

\section{Suggestions to Reduce Exposure}

Babies and infants are especially at risk from low dose BPA exposure. Here are some suggestions:

\section{Feeding}

- Breastfeed whenever possible for as long as possible. Breast milk is the optimal food for your baby, the World Health Organisation (WHO) recommends six months of exclusive

Breast feeding and continued breastfeeding thereafter until two years or longer, so no need for infant formula and bottles. - If you need to use infant formula, choose a powdered one, as liquid formulas have higher levels of BPA, and use glass bottles or cups for feeding.

- Use as few cans as possible, as the metal will probably be coated with epoxy resin which contains BPA.

- Do not use ready-to-eat liquid formulas in metal cans.

- Avoid liquid formulas that are in rigid and transparent plastic containers marked with "PC".

- When expressing breast milk, use breast pumps, shields and jars and bags that are BPA free.

Table : Screening of environmental and health properties of the possible alternatives to bisphenol A

\begin{tabular}{|c|c|c|c|c|}
\hline Focus area & $\begin{array}{l}\text { Name of } \\
\text { alternative }\end{array}$ & $\begin{array}{l}\text { Environmental } \\
\text { assessment }\end{array}$ & $\begin{array}{l}\text { Health } \\
\text { assessment }\end{array}$ & $\begin{array}{l}\text { Endo } \\
\text { crine } \\
\text { disru } \\
\text { ption' }\end{array}$ \\
\hline Coating & $\begin{array}{l}\text { Polyacrylates } \\
\text { (possible migration } \\
\text { of monomers) }\end{array}$ & $\begin{array}{l}\text { The polymers: not officially } \\
\text { classified. } \\
\text { Acrylate monomers: } \mathrm{N} ; \mathrm{R} 51 / 53\end{array}$ & $\begin{array}{l}\text { The polymers: not classified. } \\
\text { Monoalkyl or monoaryl or } \\
\text { monoalkylaryl esters of } \\
\text { acrylic acid: Xi;R36/37/38 }\end{array}$ & No \\
\hline Coating & $\begin{array}{l}\text { Polyester } \\
(63148-69-6)\end{array}$ & Not officially classified & The polymers: not classified & No \\
\hline $\begin{array}{l}\text { Polycarbo } \\
\text { nate }\end{array}$ & $\begin{array}{l}\text { Polyamides } \\
\text { Grilamid TR. } \\
\text { Polyamide (nylon) } \\
\text { Nylon } 66 \\
\text { (hexamethylene } \\
\text { adipamide) } \\
\text { (32131-17-2) } \\
\text { (3323-53-3) }\end{array}$ & $\begin{array}{l}\text { Not officially classified: The } \\
\text { available data indicate that the } \\
\text { substance should not be classified } \\
\text { as hazardous to the environment. }\end{array}$ & The polymers: not classified & No \\
\hline $\begin{array}{l}\text { Printing } \\
\text { inks }\end{array}$ & $\begin{array}{l}\text { Polyacrylates } \\
\text { (possible migration } \\
\text { of monomers) }\end{array}$ & $\begin{array}{l}\text { The polymers: Not officially } \\
\text { classified. } \\
\text { Acrylate monomers: N;R51/53 }\end{array}$ & $\begin{array}{l}\text { The polymers: not classified. } \\
\text { Monoalkyl or monoaryl or } \\
\text { monoalkylaryl esters of } \\
\text { acrylic acid: Xi;R36/37/38 }\end{array}$ & No \\
\hline $\begin{array}{l}\text { Printing } \\
\text { inks }\end{array}$ & $\begin{array}{l}\text { Polymerised rosin } \\
(8050-09-7)\end{array}$ & $\begin{array}{l}\text { Not officially classified: Possible } \\
\text { classification: } \\
\mathrm{N} ; \mathrm{R} 50 / 53\end{array}$ & $\mathrm{XI}, \mathrm{R} 43$ (N-Class, 2003) & No \\
\hline All areas & $\begin{array}{l}\text { Bisphenol A } \\
(80-05-7)\end{array}$ & $\begin{array}{l}\text { BPA does not fulfil the criteria for } \\
\text { classification (EU, 2003A). }\end{array}$ & $\begin{array}{l}\text { XI; R367/37/38 R43 (Danish } \\
\text { EPA, 2002). } \\
\text { Suggestion: } \\
\text { Repr. Cat. 3; R62 } \\
\text { Xi; R37-41, R43 (EU, 2003A) }\end{array}$ & Yes \\
\hline
\end{tabular}

\section{CONCLUSION}

The risk to humans of BPA exposure has been assessed during the last 10 years by several regulatory authorities, institutions and expert groups in Europe, the United States, Canada and Japan. Some of these risk assessments were carried out by regulatory bodies, whereas others were conducted by government-funded expert groups; in all cases, potential adverse health effects of BPA were identified and evaluated, and human exposure levels were estimated in order to draw conclusions about health risks at current exposure levels (Beronius et al., 2009). Scientific research has shown again and again that BPA is a known and proven 
endocrine disrupting chemical (a chemical that disturbs the hormone system). A 2007 scientific review linked exposure to BPA with an increased risk of cancer of the hematopoietic system(e.g. marrow, spleen, tonsils, and lymph nodes), a significant increase in cell tumours of the testes and an alteration of the number of chromosomes in some cells and tissues (potentially leading to mutations and ultimately cancer). Additionally, early life exposure may induce or predispose humans to an increased risk of breast cancer. When exposure occurs during foetal or early childhood development, BPA may increase a person's susceptibility to cancer by affecting their genetic developmental 'programming'. It is important to note that any bottle and plastic containers that are made from polyethylene terephthalate (PET) plastic, does not contain BPA. And it is highly recommended that food should be store in glass, ceramic or stainless steel containers. Also it is advice to buy fresh local products; try to avoid fruit and vegetables grown in greenhouses.

\section{REFERENCES}

[1] Abdulrahman F W , Itodo AU. Canned fish poisoning: High level of some toxic metals. Medical and Pharm. sciences 2006; 2(1):10-14.

[2] Adewale, H.B., Todd, K.L., Mickens, J.A. and Patisaul, H.B. (2011) The impact of neonatal bisphenol A exposure on sexually dimorphic hypothalamic nuclei in the female rat. Neurotoxicology 32, 38-49.

[3] Alonso-Magdalena, P., Vieira, E., Soriano, S., Menes, L., Burks, D., Quesada, I. and Nadal, A. (2010b) Bisphenol A exposure during pregnancy disrupts glucose homeostasis in mothers and adult male offspring. Environ Health Perspect 118, 1243-50.

[4] Beronius A, Rude C, Hakansson H, Hanberg A, 2009. Risk to all or none?. A comparative analysis of controversies in the health risk assessment of Bisphenol A. Reprod Toxicol doi:10.1016/j.reprotox.2009.11.007.

[5] Braun, J.M., Yolton, K., Dietrich, K.N., Hornung, R., Ye, X., Calafat, A.M. and Lanphear, B.P. 2009. Prenatal bisphenol A exposure and early childhood behavior. Environ Health Perspect 117, 1945-52.

[6] Calafat, A.et al. 2008. Exposure of the US population to bisphenol A ad 4-tertiary-octylphenol: 2003-2004. Env. Health Perspectives, 116(1), pp. 39-44.

[7] Cantonwine, D., Meeker, J.D., Hu, H., Sanchez, B.N., Lamadrid-Figueroa, H., Mercado-Garcia, A., Fortenberry, G.Z., Calafat, A.M. and Tellez-Rojo, M.M. 2010. Bisphenol a exposure in Mexico City and risk of prematurity: a pilot nested case control study. Environ Health 9, 62.

[8] Chou, W.C., Chen, J.L., Lin, C.F., Chen, Y.C., Shih, F.C. and Chuang, C.Y. 2011. Biomonitoring of bisphenol A concentrations in maternal and umbilical cord blood in regard to birth outcomes and adipokine expression: a birth cohort study in Taiwan. Environ Health 10, 94.

[9] EFSA 2008. Scientific Opinion of the Panel on Food additives, Flavourings, Processing aids and Materials in Contact with Food (AFC) on toxicokinetics of bisphenol A. The European Food Safety Authority Journal 759:1-10. Available: http://www.efsa.europa.eu/en/scdocs/scdoc/759.htm.

[10]EU (2003A). Risk assessment of bisphenol A, Final Report, October 2003.

[11] Itodo .AU, Abdulrahman FW, Happiness UO, Abubakar MN. corrosion impact on the leacheability of heavy metal ions in canned juices and beverages marketed in Nigeria . Research in Sc.,Edu,Info. And Comm tech. 2009; 1 (1), 164

[12] Lee YJ, Ryu HY, Kim HK, Min CS, Lee JH, Kim E, Nam BH, Park JH, Jung JY, Jang DD, Park EY, Lee KH, Ma JY, Won HS, Im MW, Leem JH, Hong YC, Yoon HS, 2008. Maternal and fetal exposure to bisphenol A in Korea. Reprod Toxicol 25(4) 413-9.

[13] Meeker, J.D. and Ferguson, K.K. 2011. Relationship between urinary phthalate and bisphenol A concentrations and serum thyroid measures in U.S. adults and adolescents from the National Health and Nutrition Examination Survey (NHANES) 2007-2008. Environ Health Perspect 119, 1396-402.

[14] Miao, M., Yuan, W., Zhu, G., He, X. and Li, D.K. 2011b. In utero exposure to bisphenol-A and its effect on birth weight of offspring. Reprod Toxicol 32, 64-8.

[15] Sekizawa J, 2008. Low-dose effects of bisphenol A: a serious threat to human health? J Toxicol Sci 33(4) $389-403$.

[16] Vandenberg LN, Hauser R, Marcus M, Olea N, Welshons WV, 2007. Human exposure to bisphenol A (BPA). Reprod Toxicol 24 139-177.

[17] Vandenberg, L.N., Colborn, T., Hayes, T.B., Heindel, J.J., Jacobs, D.R., Lee, D.-H., Shioda, T., Soto, A.M., Vom Saal, F.S., Welshons, W.V., Zoeller, R.T. and Myers, J.P. 2012b. Hormones and endocrine disrupting chemicals: low dose effects and non-monotonic dose responses. Endocrine Reviews online 2012 Mar 14.

[18] vom Saal FS, Myers JP 2008. Bisphenol A and Risk of Metabolic Disorders, JAMA. 2008;300(11):1353-1355 